\title{
What are the impacts of giving up the driving licence?
}

\author{
Siren, Anu Kristiina; Haustein, Sonja
}

Published in:

Ageing \& Society

Link to article, DOI:

$10.1017 / \mathrm{S} 0144686 \times 14000610$

Publication date:

2014

Document Version

Peer reviewed version

Link back to DTU Orbit

Citation (APA):

Siren, A. K., \& Haustein, S. (2014). What are the impacts of giving up the driving licence? Ageing \& Society, 35(9), 1821-1838. https://doi.org/10.1017/S0144686X14000610

\section{General rights}

Copyright and moral rights for the publications made accessible in the public portal are retained by the authors and/or other copyright owners and it is a condition of accessing publications that users recognise and abide by the legal requirements associated with these rights.

- Users may download and print one copy of any publication from the public portal for the purpose of private study or research.

- You may not further distribute the material or use it for any profit-making activity or commercial gain

- You may freely distribute the URL identifying the publication in the public portal

If you believe that this document breaches copyright please contact us providing details, and we will remove access to the work immediately and investigate your claim. 
What are the impacts of giving up the driving licence?

\author{
Anu Siren* \\ The Danish National Centre for Social Research, \\ Herluf Trolles Gade 11, DK-1052Copenhagen, Denmark \\ Tel.: +4533697753 \\ E-mail: anu@sfi.dk
}

Sonja $\underline{\text { Haustein }}$

Department of Transport, Technical University of Denmark,

Bygningstorvet 115, DK-2800 Kgs. Lyngby, Denmark

Tel.:+4545256519

E-mail:sonh@transport.dtu.dk

*Corresponding author

\begin{abstract}
Driving cessation is a gradual process, where driver's self-regulation plays an important role. Agebased licence renewal may interfere with this process and trigger premature driving cessation. The present study compares Danish drivers (aged 69 years at the baseline) who either renewed or gave up their driving licence. Data were collected in $2009(n=1,792)$ and in $2012(n=863)$. The standardized interviews covered respondents' background information, health and well-being, and
\end{abstract}


transportation patterns. Non-renewers had poorer health already at baseline but did become more dependent on others in their activities after giving up their licence. In travel frequency, neither the differences between renewers and non-renewers nor the changes over time within the groups were pronounced. The groups differed in their use of transport modes already at the baseline: the renewers drove, while non-renewers travelled as passengers, used public transport, walked or cycled. Not renewing the license was a strong predictor of unmet mobility needs, especially in relation to leisure activities. The present study indicates that younger seniors' mobility is not likely to be affected by the strict renewal policies. However, given the positive economic and safety consequences of independent mobility in old age, society should try to prevent unwarranted mobility loss. Having restrictive, ageist policies that moreover fail as societal investments, may work against this goal.

Keywords: Driving cessation, mobility needs, health outcomes 


\section{Introduction}

\section{Driving cessation and driver licensing legislation}

Driving is an important means of transportation for older people and driving cessation is likely to decrease both mobility and safety of the former drivers, since alternative travel options are often insufficient, unattractive and less safe (Organization for Economic Cooperation and Development [OECD] 2001). Previous research has shown that driving cessation is associated with a decrease in activities outside the home (Harrison and Ragland 2003Marottoliet al. 2000; Rosenbloom 2001) as well as adecrease in experienced mobility options (Peel, Westmoreland and Steinberg 2002; Taylor and Tripodes 2001). In addition, previous studies have found driving cessation to be associated with negative health outcomes, such as increasing depressive symptoms (Fonda,Wallace and Herzog 2001; Marottoli et al. 1997; Ragland, Satariano and McLeod 2005), decreased life satisfaction (Harrison and Ragland 2003) and declines in physical and social functioning (Edwards et al. 2009; Mezuk and Rebok 2008).

It has been proposed that driving cessation, unless caused by an accident or sudden change in functionality, is a gradual process where driver's self-regulation plays an important role (e.g., Dellinger et al. 2001; Hakamies-Blomqvist and Wahlström 1998). That is, drivers gradually reduce and limit their driving before giving up completely. This allows the individual to adapt to changes in mobility options and to find alternatives, if available, to car driving. This is further supported by recent findings showing that older people who pre-plan their driving cessation show a relatively higher quality of life(Musselwhite and Shergold 2013) and get their mobility needs fulfilled post driving cessation (Musselwhite, 2010).

However, licence renewal policies with age-based mandatory screening that are used in many countries have been claimed to interfere with this gradual and voluntary process, making many older people stop driving, often somewhat prematurely (Hakamies- 
BlomqvistandWahlström1998; Langford and Koppel 2006). It has been shown that especially older women are vulnerable to renewal policies and often choose not to renew their licence, although they are still fit to drive (Hakamies-Blomqvist and Wahlström 1998; Siren, Hakamies-Blomqvist and Lindeman 2004; Siren, Haustein and Meng 2012; Wilkins, Stutts and Schatz 1999). An abrupt driving cessation might result in loss of control over managing one’s personal mobility and adapting to the changes. Previous research has shown that perceived control plays an important role in development of depressive symptoms post-driving cessation (Windsoret al. 2007; see also Musselwhite \& Shergold, 2013).

Licence renewal policies with age-based screening are not evidence-based and have thuscome under heavy criticism (Desapriya, Ranatunga and Pike 2012; Langford and Koppel 2006; O’Neill 2012a,b). Research has not been able to show that age-based screening would generate any safety benefits - in fact, quite the contrary (e.g., Hakamies-Blomqvist, Johansson and Lundberg, 1996; Siren and Meng 2012; Tay 2012). In addition, it is believed that age-based screening procedures trigger premature driving cessation and consequently cause restrictions in personal mobility (Langford and Koppel 2006).It is, however, unclear how great an effect these policies as such may have on older people’s mobility and well-being. That is, does having a licence renewal policy indeed make older drivers stop driving and, further, create mobility and health consequences? The earlier studies demonstrating seniors' vulnerability to these policies described somewhat older cohorts of seniors (e.g., Hakamies-Blomqvist and Wahlström 1998; Mitchell, 2008), and one could expect that the mobility of the new, more car-reliant cohorts may be less affected by the renewal policies (cf., Choi and Mezuk, 2013).

Background and aim of the present study

There is a considerable heterogeneity of licence renewal policies in Europe (Siren et al. 2013), and the periodicity of renewal, requirement for driver assessments, the age of first 
assessment, and the methods used in the assessment vary greatly. In Denmark, a driving licence is valid for 15 years at a time, until the driver reaches the age of 70 . Thereafter, the licence needs to be renewed at the age of $70,74,76,78$ and 80 . After the age of 80 , the licence has to be renewed every year. In order to renew their licence after the age of 70 years, a person has to go through a medical check performed by a physician including a short version of the mini-mental examination (mMMSE, cf. Folstein, Folstein and McHugh 1975) and the clock drawing test (cf. Critchley 1953; Shulman, Shedletsky and Silver 1986). If the physician is undecided about the applicant's fitness to drive, the applicant undergoes a practical driving test.

The present study examines giving up the driving licence and the consequences that it has on the mobility and well-being of Danish seniors whose driving licence expired for the first time at the age of 70. More specifically, we investigate first, if not renewing the licence is a transition point that abruptly affects mobility, and second which changes in mobility patterns, unfulfilled mobility needs, and physical and psychological well-being can be observed over a twoyear period in older drivers who either gave up or renewed their licence.

\section{Materials and methods}

\section{The procedure}

Data for this study were collected by interviewing a sample of older Danish persons at baseline in $2009(n=1,792)$ and at follow-up in $2012(n=863)$. The baseline interviews were conducted from November to December in 2009, and the follow-up interviews from January to February in 2012. The data were collected by means of standardized computer-assisted telephone interviews (CATI) carried out by Ipsos Marketing (at the time Synovate Denmark A/S). 
For the first survey, a random sample of citizens who turned 70 between November 2009 and February 2010 (belonging to cohorts 1939 and 1940) was drawn from the Danish civil registration system. Because the group not intending to renew their licence in 2009 was small, in the second survey they were contacted first in order to achieve the necessary number of participants neededfor comparing those who did renew their licence and those who did not. The rest of the sample at follow-up was collected randomly among those who participated in 2009. Both times the target population received a letter announcing the survey.

Altogether, 1792 interviews were conducted in 2009 and 863 in 2012. After correcting for telephone/address errors, people who were unable to be interviewed due to language barriers or illness and people who were not contacted because the number of intended interviews had already been achieved, the overall response rate was 70 per cent (15\% refusals, 15\% not reached) in 2009 and 77 per cent in 2012 (20\% refusals, 4\% not reached).

\section{Measures}

The standardized interviews were based on an ad hoc questionnaire. The interviews took an average of 25 minutes to complete. In the following section, the parts of the questionnaire which are analyzed in the present article are described in detail.

Background information: this included gender, education, family status (married/living with a partner, single, widowed), and personal income. In addition, the participants were asked if they intended to renew their driving licence when turning 70 years old.

Health and well-being: participants were asked to rate their overall health on a fourpoint rating scale (excellent, good, fair or poor). As an objective measure of health status, the participants were presented with a list of 20 symptoms and illnesses and asked to indicate whether they suffered from these as confirmed by a physician. This list was derived from previous studies with a similar setting and subjects (e.g., Siren, Hakamies-Blomqvist and Lindeman 2004). Because 
only some of the illnesses and symptoms impair the ability to drive, illnesses and symptoms were further classified into three categories: illnesses impairing driving ability (cataract or glaucoma, stroke or brain infarction, dementia, and short-term unconsciousness), illnesses possibly impairing driving ability (chest pain, vertigo, heart defect, diabetes, heart infarction, Parkinson’s disease, and epilepsy), and illnesses not impairing driving ability (pain in joints, high blood pressure, blood circulation problems in legs or feet, lung diseases, cancer, hyperthyroid or hypothyroid disease, anemia, and vitamin deficit). The categories were based on the work by Janke (1994).

In addition, individual well-being was measured by the CES-D depression scale (e.g., Radloff 1977) and the Pearlin mastery scale (Pearlin and Schooler 1978). The CES-D scale is a short self-report scale designed to measure depressive symptomatology in the general population. The Pearlin mastery scale measures the extent to which a person perceives her/himself to be in control of events and ongoing situations. Both scales showed acceptable internal consistencies (Cronbach's alpha) at both survey times (CES-D depression scale: $\alpha(2009)=.67 ; \alpha(2012)=$ $.68 ;$ Pearlin mastery scale $\alpha(2009)=.79 ; \alpha(2012)=.77)$.

Modal choices and transport patterns: these were assessed by participants’ specifications about different everyday activities (see Figure 1 for the list of activities). Individuals were asked about activity frequency (using a six-point scale from [almost] never to [almost] everyday) and the most common mode of transport for each activity (by car as driver; by car as passenger; by public transport; by taxi; by motorbike; cycling; walking; by plane (only for some activities); by other modes of transport). To cover the respondents' unmet travel needs, we used a set of questions that have been used in previous studies to obtain information on unmet/uncovered transport needs (Hjorthol, 2013), unfulfilled travel needs (Siren \& Hakamies-Blomqvist, 2004) or unfulfilled activity wishes (Scheiner, 2006). The respondents were asked "if there were no barriers, would you leave home more often to pursue the following activities” (a lot more often; somewhat 
more often; not more often; see Figure 1 for the list of activities). The interviewer was instructed to elaborate "barriers" as physical impediments, lack of transport or transport costs.

Dependency on others: this was assessed by asking how dependent the participants were on other people for their transportation when leaving home (using a four-point scale: not at all; only a little; to some degree; to a high degree).

\section{Respondents}

In this paper, the focus is on respondents who took part in both surveys. This group $(n=863)$ consisted of 456 women (52.8\%) and 407 men (47.2\%), aged 71 (75.0\%) and 72 (25.0\%) in 2012. Most of them had a spouse (72.0\% were married or cohabitating), while 17.3 per cent were widowed and 10.8 per cent single. Almost all respondents were retired (96.1\%). The average personal annual income was approximately €25,600. Regarding education, 27.4 per cent had a basic school education, whereas 26.2 per cent had a (medium or long-cycle) higher education. The sample was representative in terms of gender and percentage of widowed persons. However, the income was somewhat below average, whereas the educational level of the sample was above average. The lower income might be due to a high number of missing values regarding income (32.4\%).It is possible that especially people with higher incomes refused to answer this question. The higher education status of the sample is probably due to a higher willingness to participate among people with higher education.

People who took part in both surveys did not differ significantly from people who only took part in the first survey with regard to all background variables described earlier. They also did not differ significantly with regard to their health status.

Of the 771 respondents who reported to be licensed in the first survey, 80 people (10.4\%) did not renew their licence(“non-renewers”) and 691 (89.6\%) did (“renewers”). The majority of non-renewers $(75 \%, n=60)$ intended not to renew the license before they turned $70,19 \%$ 
$(n=15)$ intended to renew, and 6\% $(n=5)$ were undecided. Any possible subgroups of non-renewers were too small to be distinguished, and further, it is unknown if those who intended to renew but finally did not, changed their mind or failed the medical examination. Non-renewers and renewers will be compared according to their demographics, health and well-being, dependency on others, travel patterns, and unmet mobility needs before and after renewal.

\section{Analysis}

To test whether renewers differed significantly from non-renewers with regard to demographics, health-related variables, attitude and behavior, Pearson's $\chi^{2}$ test, Mann-Whitney U-test, and t-tests for independent samples were used as appropriate. To test for differences within the groups of renewers or non-renewers comparing 2009 and 2012 data, McNemar’s test, Wilcoxon test, and ttest for related samples were used. Finally, a simultaneous linear regression analysis was conducted to test whether not renewing the license had a significant impact on unmet mobility needs, when sociodemographic and health variables were controlled for.

\section{Results}

\section{Demographics of renewers and non-renewers}

There was a significant gender difference with regard to renewing the licence or not, $\chi^{2}$ $(1,771)=29.49, p<.001$. While 62 out of the 80 non-renewers were women $(77.5 \%)$, the gender distribution among renewers was more balanced (45.4\% women). Further, it was more likely for people who lived together with a partner to renew the licence (92.6\% renewed) than for those who were single $(75.7 \%)$ or widowed $(82.9 \%), \chi^{2}(2,771)=26.17, p<.001$. The percentage of people who renewed the licence was further higher outside the city of Copenhagen (90.3\%) than within (70.4\%), $\chi^{2}(1,771)=11.15, p<.001$, probably because of the higher car dependency outside the 
capital and the better infrastructural alternatives within. By contrast, there was no significant difference between people with different forms of education with regard to the likelihood of renewing the licence of not, $\chi^{2}(6,769)=7.67, p>.10$. Finally, people who renewed the licence had a higher average income, $t(652)=2.89, p<.05$, which was, however, partly due to the lower average income of women who were less likely to renew the licence than men. In the subsamples of men/women the income differences were not significant.

\section{Health, well-being and dependency on others}

With regard to all health-related variables - except for mastery - non-renewers differed from renewers by having poorer health both in 2009 and 2012. As Table 1 shows, most of the differences are statistically significant. With regard to mastery, the groups did not differ significantly from each other but showed a similar significant decline from 2009 to 2012. Also in the other health variables there was a decline from 2009 to 2012 in both groups, but not all of these differences are statistically significant (see Table 1). Overall, the differences in health and well-being seem to be a cause rather than an effect of driving cessation. One exception is dependency on others for transport, which tendentiously declines in the group of non-renewers $(p=.52)$. Regarding this variable we find the greatest difference between renewers and non-renewers at both survey times, with a much higher percentage of non-renewers being dependent on others already before, but especially after not renewing the licence.It is however unclear, to which extent the respondents experienced being dependent on others as something negative. Mastery and dependency on others were only weakly, although significantly, correlated (baseline: $r=.11^{* *}$; follow up: $r=.12^{* *}$ ), indicating that the respondents to a large degree did not experience dependency on others as loss of control.

$<$ Insert Table 1 about here $>$ 


\section{Travel patterns}

For each everyday activity, the respondents indicated how often they conducted these. As Figure 1 illustrates, neither the differences between renewers and non-renewers nor the changes over time within the groups are very pronounced. Yet some statistically significant differences can be observed.

In 2009 non-renewers went shopping more often than renewers, $U=23700.5, p<.05$, travelled more often in relation to health care, $U=23672.5, p<.01$, and went out more often without a special purpose, $U=23838.5, p<.05$. In 2012 the non-renewers travelled less often in relation to running errands to the bank, post office and so on, $U=21681.5, p<.001$. For renewers, the frequencies in relation to running errands to the bank, post office and so on (Wilcoxon: $Z=$ 4.21, $p<.001)$, pursuing one's hobbies $(Z=-2.57, p<.01)$ and visiting friends (nearby: $(Z=-3.71$, $p<.001)$ and farther away: $(Z=-2.18, p<.05))$ declined significantly from 2009 to 2012 . We found comparable decreases in activities for the group of non-renewers, but these did not reach the level of significance, probably due to the smaller sample size. In the case of travelling in relation to health care, the renewers' frequency increased (coming from a lower level; $Z=-22.18, p<.001$ ), whereas non-renewers’ frequency slightly decreased $(Z=-2.36, p<.05)$.

$<$ Insert Figure 1 about here $>$

The groups differed significantly in their use of transport modes both in 2009 and 2012. The renewers drove a car more often as the main transport mode, while non-renewers only rarely did so but travelled in the car as a passenger, used public transport, walked or cycled, as Figures 2 and 3 illustrate. The differences between the groups in terms of modal choice are even more 
pronounced in 2012. The differences between the groups were significant for all activities ( $p<$ $.001)$.

The changes in mode choice from 2009 to 2012 were rather small within the groups. The only clear pattern is an increase in car use as passengers in both groups. This change is more marked in the group that is not licensed to drive anymore. However, also for renewers the difference in mode choice (“car as driver” vs. "car passenger” vs. "other modes”) between 2009 and 2012 became significant in four out of seven purposes. With regard to going to the post or bank people used the car more often as passenger in 2012 especially at the expense of walking (McNemar test: $\left.\chi^{2}(3,371)=14.67, p<.01\right)$, with regard to family/friends farther away at the expense of driving $\left(\chi^{2}(3,609)=17.96, p<.001\right)$ and with regard to shopping $\left(\chi^{2}(3,674)=10.60\right.$, $p<.05)$ and visiting family and friends nearby $\left(\chi^{2}(3,667)=14.90, p<.01\right)$ at the expense of both walking and driving (see also Figure 3).

$<$ Insert Figure 2 about here $>$

$<$ Insert Figure 3 about here $>$

\section{Unmet mobility needs}

Non-renewers reported more unmet mobility needs both in 2009 and 2012, especially in relation to leisure activities (see Figure 2). However, in 2012 differences between renewers and non-renewers were a bit more pronounced. It is especially unmet needs in leisure activities that increase for nonrenewers: visiting friends and family, pursuing hobbies and going out without a special purpose, although the change from 2009 to 2012 is statistically significant only with regard to visiting friends and relatives close by (Wilcoxon: $Z=-2.07, p<.05$ ).

\footnotetext{
$<$ Insert Figure 4 about here $>$
} 
A set of regression analyses was conducted in order to examine if not renewing the licence significantly increased unmet mobility needs (see Table2). The results confirm that not renewing the license is related to a higher degree of unmet mobility needs, even if demographic and health variables are controlled for. Both in 2009 and 2012, the strongest predictors of unmet mobility needs are physical and mental well-being along with the renewal status. This also confirms that the non-renewers were likely to have already ceased driving in 2009. The main difference between 2009 and 2012 is the role of mastery as a significant predictor for unfulfilled mobility needs. A possible explanation is that holding a license but not using it (or not being able to use it due to lack of resources or driving confidence, for example) may contribute to feeling of lacking mastery in one’s life (the scale included statements like 'I have no control over things in my life').

$<$ Insert Table 2 about here $>$

\section{Discussion}

The aim of the present study was to investigate the changes in mobility patterns, unfulfilled mobility needs, and physical and psychological well-being over a two-year period in older drivers who either gave up or renewed their driving licence. There were four main findings.

First, those not renewing their driving licence had poorer health already at the baseline and the decreases in health during the observation period were similar for both groups. However, compared to the renewers in the same period, the non-renewers did become more dependent on others in their out-of-home activities after giving up theirlicence. Second, when it comes to travel frequency, neither the differences between renewers and non-renewers nor the changes over time within the groups were very pronounced. The trip frequency in general declined somewhat for both groups. Third, the groups differed significantly in their use of transport modes, both in 2009 and 
2012. The renewers drove a car more often as the main transport mode, while non-renewers travelled in the car as a passenger, used public transport, walked or cycled. Both groups increased their share of travelling as a passenger during the two-year period but, overall, the differences between the groups in terms of modal choice became even more pronounced in 2012. Finally, nonrenewers reported more unmet mobility needs both in 2009 and 2012, especially in relation to leisure activities. This difference became slightly more pronounced during the observation period. The unmet mobility needs were significantly associated with non-renewal even when controlling for a number of co-variables.

The differences in health found between the groups seem to be rather a cause than an effect of giving up their driving licence. Previous research has documented health consequences from driving cessation (Edwards et al. 2009; Fonda et al. 2001; Marottoli et al. 1997; Mezuk and Rebok 2008; Ragland et al. 2005), but the observation periods in these studies tend to be longer, and the focus has been on the actual driving cessation, not the administrative driving cessation that is, handing in their licence. Given that the present results indicate that many non-renewers had already ceased driving at baseline, the differences found in health may reflect consequences of driving cessation that happened earlier.

Travel frequency did not appear to be affected by renewal/non-renewal of their driving licence, and the two groups did not differ notably in their trip frequency, even at baseline. This is somewhat surprising, as previous research has indicated declines in out-of-home activities after driving cessation (Harrison and Ragland 2003; Marottoli et al. 2000; Rosenbloom 2001). Perhaps in a Danish context, the frequency of out-of-home activities is not as dependent on car access as in other contexts, such as in the United States. However, we found a clear difference in terms of unfulfilled mobility needs, especially as regards leisure activities, indicating a difference in the experienced mobility. Leisure activities tend to require more complex and individualized travel 
compared to work or shopping trips (Scheiner 2010), which makes these activities more dependent on car availability. The higher level of unfulfilled mobility needs among the non-renewers probably also reflects general disadvantage of this group compared to renewers, including poorer health and functionality. In line with this, public transport-related problems and health restrictions have been found among the most often reported reasons for unmet travel needs (Kasper and Scheiner 2005).However, the when controlling for health and other background variables, the renewal status still remained as a significant predictor of unfulfilled mobility needs.

The present study indicates that the licence renewal policy as such has only a small effect on the drivers that have to renew their licence for the first time at the age of 70 . The current cohorts turning 70 years old are not likely to abruptly give up their licence. Only a small proportion chooses to not renew the licence when it expires, and these licence holders have ceased driving already earlier. The present study could not provide conclusive evidence on the health impacts from driving cessation and it remains unclear, to which extent driving cessation affects or is affected by health. We found that depression and some illnesses increased for non-renewers, but the causation is not clear. Nevertheless, this study could demonstrate that giving up the driving licence (and the self-regulatory driving behaviour that often seems to occur prior licence surrender) are strongly related to unfulfilled mobility needs. This indicates that efforts in preventing premature driving cessation may be beneficial for the society.

The present study had the advantage of a longitudinal design and a large and representative sample. However, the sample of non-renewers was small, especially the number of male non-renewers. This made it in some cases difficult to test the significance of the differences found between renewers and non-renewers and it was not possible to control for gender, family status and residential area, variables which were found related to renewing the licence or not. All in all, when interpreting the results, it has to be kept in mind that three quarters of non-renewers are 
women. For a small part of non-renewers (15\%) it is unclear whether they intentionally did not renew their licence or whether they wanted to renew it but were rejected. It can be expected that those who remained in control of giving-up driving faced less problems related to quality of life than those when were forced to give up (Musselwhite and Shergold, 2013; Windsor et al. 2007). Another limitation of the study was that the follow-up period was not very long, making it more difficult to capture the possible changes in health and well-being post-driving cessation. Finally, the study addressed only older drivers aged 69 years at baseline. Thus the results are not generalizable to all older Danish drivers, but only to the youngest cohorts of seniors. While the present study indicates that the younger seniors are not vulnerable to the driver licensing policies, this may be different in the older cohorts as well as later on when these younger cohorts reach older ages and have to renew their licence again.

Age-based screening practices can be seen as ageist policies that signalize that the society finds car driving by senior citizens a questionable, even suspect activity. At the same time, the senior population is increasingly active and car-reliant, wishing to continue driving into advanced ages. The present study indicates that younger seniors' mobility is not likely to be affected by the strict renewal policies, as the majority will continue driving despite the renewal procedure. While driving cessation was associated with mobility problems, those persons not renewing their licenses had already restricted their driving or stopped driving entirely before reaching the renewal age. The economic and safety returns of the age-based driver screening policies have been shown to be poor (Langford et al. 2004; Siren and Meng 2012) and some studies indicate that having such policies in place may actually decrease the safety (Hakamies-Blomqvist et al., 1996; Siren \& Meng, 2012, Tay, 2013). At the same time, the economic and safety benefits of independent mobility in old age are indisputable (e.g., Hakamies-Blomqvist, 2003) making prevention of premature driving cessation and the consequent mobility loss justified. Having 
restrictive, ageist policies in place that moreover fail as societal investments, may however work against society’s goal of preventing unwarranted mobility loss in old age. 


\section{References}

Choi, M. and Mezuk, B. 2013. Aging without driving: Evidence from the health and retirement study, 1993 to 2008. Journal of Applied Gerontology, 32, 7, 902-912.

Critchley, M. 1953. The parietal lobes. Hafner Publishing Company, New York, NY.

Dellinger, A.M., Sehgal, M., Sleet, D.A. and Barrett-Connor, E. 2001. Driving cessation: What older former drivers tell us.Journal of the American Geriatrics Society,49, 4, 431-5.

Desapriya, E., Ranatunga, Y. and Pike, I. 2012. We need evidence based tools to identify medically at risk drivers. $B M J, 345$, e7087.

Edwards, J. D., Lunsman, M., Perkind, M., Rebok, G.W. and Roth, D.L. 2009.Driving cessation and heath trajectories in older adults. Journals of Gerontology: Medical Sciences,64A, $12,1290-5$.

Folstein, M.F., Folstein, S.E. and McHugh, P.R. 1975. "Mini-mental state".A practical method for grading the cognitive state of patients for the clinician.Journal of Psychiatric Research, 12, 3, 189-98.

Fonda, S.J., Wallace, R.B. andHerzog, A.R. 2001.Changes in driving patterns and worsening depressive symptoms among older adults.Journals of Gerontology: Series B: Psychological Sciences \& Social Sciences,56B, 6, S343-51.

Hakamies-Blomqvist, L. 2003. Ageing Europe. The challenges and opportunities for transport safety. Fifth European Traffic Safety Lecture. Bruxelles: European Transport Safety Council.

Hakamies-Blomqvist, L. and Wahlström, B. 1998. Why do older drivers give up driving? Accident Analysis and Prevention, 30, 3, 305-12. 
Hakamies-Blomqvist, L., Johansson, K. and Lundberg, C. 1996. Medical screenings of older drivers as a traffic safety measure-a comparative Finnish-Swedish evaluation study. Journal of American Geriatrics Society, 44, 6, 650-653.

Harrison, A. and Ragland, D.R. 2003.Consequences of driving reduction or cessation for older adults. Transportation Research Record, 1843, 96-104.

Janke, M.K. 1994. Age-related disabilities that may impair driving and their assessment. California State Department of Motor Vehicles, National Highway Safety Administration, Sacramento, CA.

Kasper, B. and Scheiner, J. 2005. Spatial development and leisure mobility in an ageing society. In Williams, K.(ed.), Spatial planning, urban form and sustainable transport. Ashgate, Aldershot, UK, 83-101.

Langford, J. and Koppel, S. 2006. The case for and against mandatory age-based assessment of older drivers. Transportation Research Part F, 9, 5, 353-62.

Langford J., Fitzharris, M., Koppel, S. and Newstead, S. 2004.Effectiveness of mandatory license testing for older drivers in reducing crash risk among urban older Australian drivers.Traffic Injury Prevention, 5, 4, 326-35.

Marottoli, R., Mendes de Leon, C., Glass, T., Williams, C., Cooney, L. and Berkman, L. 2000. Consequences of driving cessation: Decreased out-of-home activity levels. Journal of Gerontology: Social Science, 55B, 6, S334-40.

Marottoli, R., Mendes de Leon, C., Glass, T., Williams, C., Cooney, L. J., Berkman, L. and Tinetti, M. 1997. Driving cessation and increased depressive symptoms: Prospective evidence from the New Haven EPESE. Journal of American Geriatric Society, 45, 2, 202-6.

Mezuk, B. and Rebok, G. W. 2008.Social integration and social support among older adults following driving cessation.Journal of Gerontology: Social Sciences, 63B, 5, S298-303. 
Mitchell, C. G. B. 2008. The licensing of older drivers in Europe -A case study.Traffic Injury Prevention, 9, 5, 360-366.

Musselwhite, C.B.A. and Shergold,I. 2013. Examining the process of driving cessation in later life. European Journal of Ageing 10, 2, 89-100.

Musselwhite, C. 2010.The role of education and training in helping older people to travel after the cessation of driving. International Journal of Education and Ageing, 1, 2, 197-212.

Organization for Economic Cooperation and Development (OECD) 2001.Ageing and Transport: Mobility Needs and Safety Issues. OECD, Paris, France.

O’Neill, D. 2012a. More mad and more wise. Accident Analysis \& Prevention, 49, 263-265.

O’Neill, D. 2012b. Medical screening of older drivers is not evidence based. BMJ, 345, e6371.

Pearlin, L.I. and Schooler, C. 1978. The structure of coping. Journal of Health and Social Behaviour, 19, 1, 2-21.

Peel, N., Westmoreland, J. and Steinberg, M. 2002. Transport safety for older people: A study of their experiences, perceptions and management needs. Injury Control and Safety Promotion, 9, 1, 19-24.

Radloff, L.S. 1977. The CES-D scale: A self-report depression scale for research in the general population. Applied Psychological Measurement,1, 3, 385-401.

Ragland, D.R., Satariano, W.A. and MacLeod, K.E. 2005.Driving cessation and increased depressive symptoms. Journal of Gerontology: Medical sciences, 60A, 3, 399-403.

Rosenbloom, S. 2001. Driving cessation among older people. When does it happen and what impact does it have? Transportation Research Record, 1779, 93-9.

Scheiner, J. 2006. Does the car make elderly people happy and mobile? Settlement structures, car availability and leisure mobility of the elderly. European Journal of Transport and Infrastructure Research, 6, 2, 151-72. 
Scheiner, J. 2010. Social inequalities in travel behaviour: Trip distances in the context of residential self-selection and lifestyles. Journal of Transport Geography, 18, 6, 679-90.

Shulman, K.I., Shedletsky, R. and Silver, I.L. 1986. The challenge of time: clock-drawing and cognitive function in the elderly. International Journal of Geriatric Psychiatry, 1, 2, 135-40.

Siren, A., Hakamies-Blomqvist, L. and Lindeman, M. 2004.Driving cessation and health in older women. Journal of Applied Gerontology, 23, 1, 58-69.

Siren, A., Haustein, S., and Meng, A. (2012). Hvilke ældre bilister fornyer deres kørekort og hvorfor? (Which older drivers renew their license and why?). DTU Transport, Report 7, Kgs. Lyngby.

Siren, A., Haustein, S., Meng, A., Bell, D., Pokriefke, E., Lang, B., Fernandez Medina, K., Gabaude, C., Marin-Lamellet, C., MonterdeiBort, H. and Strnadova, Z. 2013.Driver Licensing Legislation. Report 5.1 of the EU project CONSOL.

Siren, A. and Meng, A. 2012. Cognitive screening of older drivers does not produce safety benefits. Accident Analysis and Prevention, 45, 634-8.

Tay, R. 2012. Ageing driver licensing requirements and traffic safety. Ageing and Society, 32, 4, 655-72.

Taylor, B.D. and Tripodes, S. 2001. The effects of driving cessation on the elderly with dementia and their caregivers. Accident Analysis and Prevention, 33, 4, 519-28.

Wilkins, J.W., Stutts, J.C. and Schatz, S.J. (1999). Premature reduction and cessation of driving: Preliminary study of women who choose not to drive or to drive infrequently. Transportation Research Record, 1693, 86-90. 
Windsor, T.D., Anstey, K.J., Butterworth, P., Luszcz, M.A. and Andrews, G.R. (2007). The role of perceived control in explaining depressive symptoms associated with driving cessation in a longitudinal study. Gerontologist, 47, 2, 215-223. 
Table 1: Health and dependency variables for renewers and non-renewers 2009 and 2012

\begin{tabular}{|c|c|c|c|c|c|c|c|c|}
\hline & \multicolumn{3}{|c|}{ Renewers } & \multicolumn{3}{|c|}{ Non-renewers } & \multicolumn{2}{|c|}{ Renewers vs. non-renewers } \\
\hline & 2009 & 2012 & 2009-2012 & 2009 & 2012 & $2009-2012$ & 2009 & 2012 \\
\hline $\begin{array}{l}\text { Illnesses impairing } \\
\text { driving ability }\end{array}$ & $14.9 \%$ & $19.2 \%$ & $\begin{array}{l}\text { Mc Nemar } \\
p<.01\end{array}$ & $31.2 \%$ & $31.2 \%$ & $\begin{array}{l}\text { Mc Nemar } \\
\text { ns }\end{array}$ & $\begin{array}{l}x^{2} \text {-test } \\
p<.001\end{array}$ & $\begin{array}{l}x^{2} \text {-test } \\
p<.05\end{array}$ \\
\hline $\begin{array}{l}\text { Illnesses possibly } \\
\text { impairing driving } \\
\text { ability }\end{array}$ & $22.7 \%$ & $25.6 \%$ & $\begin{array}{l}\text { Mc Nemar } \\
p<.10\end{array}$ & $25.0 \%$ & $38.8 \%$ & $\begin{array}{l}\text { Mc Nemar } \\
p<.05\end{array}$ & $\begin{array}{l}x^{2} \text {-test } \\
n s\end{array}$ & $\begin{array}{l}x^{2} \text {-test } \\
p<.05\end{array}$ \\
\hline $\begin{array}{l}\text { Illnesses not } \\
\text { impairing driving } \\
\text { ability }\end{array}$ & $69.3 \%$ & $73.8 \%$ & $\begin{array}{l}\text { Mc Nemar } \\
p<.05\end{array}$ & $82.5 \%$ & $83.8 \%$ & $\begin{array}{l}\text { Mc Nemar } \\
\text { ns }\end{array}$ & $\begin{array}{l}x^{2} \text {-test } \\
p<.05\end{array}$ & $\begin{array}{l}\mathrm{X}^{2} \text {-test } \\
n s\end{array}$ \\
\hline $\begin{array}{l}\text { Subjective health } \\
\text { (\% in good or } \\
\text { excellent health) }\end{array}$ & $94.7 \%$ & $92.7 \%$ & $\begin{array}{l}\text { Wilcoxon } \\
p<.10\end{array}$ & $80.0 \%$ & $78.8 \%$ & Wilcoxon $n s$ & $\begin{array}{l}x^{2} \text {-test } \\
p<.001\end{array}$ & $\begin{array}{l}\text { U-test } \\
p<.001\end{array}$ \\
\hline Depression (Mean) & 12.96 & 12.88 & $\begin{array}{l}t \text {-test } \\
n s\end{array}$ & 14.18 & 14.58 & $\begin{array}{l}t \text {-test } \\
n s\end{array}$ & $\begin{array}{l}t \text {-test } \\
p<.01\end{array}$ & $\begin{array}{l}t \text {-test } \\
p<.001\end{array}$ \\
\hline Mastery (Mean) & 22.75 & 22.08 & $\begin{array}{l}t \text {-test } \\
p<.001\end{array}$ & 22.86 & 21.48 & $\begin{array}{l}t \text {-test } \\
p<.01\end{array}$ & $\begin{array}{l}t \text {-test } \\
n s\end{array}$ & $\begin{array}{l}t \text {-test } \\
n s\end{array}$ \\
\hline $\begin{array}{l}\text { Dependency } \\
\text { (\% not dependent } \\
\text { at all) }\end{array}$ & $94.2 \%$ & $92.6 \%$ & $\begin{array}{l}\text { Mc Nemar } \\
\text { ns }\end{array}$ & $67.5 \%$ & $55.0 \%$ & $\begin{array}{l}\text { Mc Nemar } \\
p<.10\end{array}$ & $\begin{array}{l}x^{2} \text {-test } \\
p<.001\end{array}$ & $\begin{array}{l}\mathrm{X}^{2} \text {-test } \\
p<.001\end{array}$ \\
\hline
\end{tabular}

$n s=$ not significant. Because of the small sample size (esp. in the group of non-renewers), results at the significance level of $10 \%$ are also reported. 
Table 2: Linear regression analysis predicting unmet travel needs in 2009 and 2012 (sum score over all activities)

\begin{tabular}{|c|c|c|c|c|c|c|}
\hline & 2009 & & & 2012 & & \\
\hline & B & SE & ß & B & SE & ß \\
\hline (will not) renewed the license & .57 & .15 & $.13 * \star \star$ & .48 & .14 & .12 *** \\
\hline Gender (male) & .05 & .09 & .02 & .05 & .08 & .02 \\
\hline Living together with a partner & -.12 & .10 & -.04 & -.16 & .09 & -.06 \\
\hline Living in Copenhagen & -.13 & .22 & -.02 & -.12 & .19 & -.02 \\
\hline Subjective health ( $1=$ excellent; $4=$ poor $)$ & .16 & .07 & $.08 *$ & .33 & .06 & $.19 * * *$ \\
\hline Depression & .04 & .01 & $.12^{\star \star}$ & .03 & .01 & $.09 *$ \\
\hline Mastery & -.05 & .01 & $-.13^{\star \star \star}$ & -.01 & .01 & -.03 \\
\hline Illnesses impairing driving & .06 & .12 & .02 & .17 & .09 & .06 \\
\hline Illnesses possibly impairing driving & -.07 & .11 & -.02 & .12 & .09 & .05 \\
\hline Illnesses not impairing driving & .08 & .10 & .03 & -.02 & .09 & -.01 \\
\hline
\end{tabular}

$R^{2}=.11 ;$ adjusted $R^{2}=.10$ 


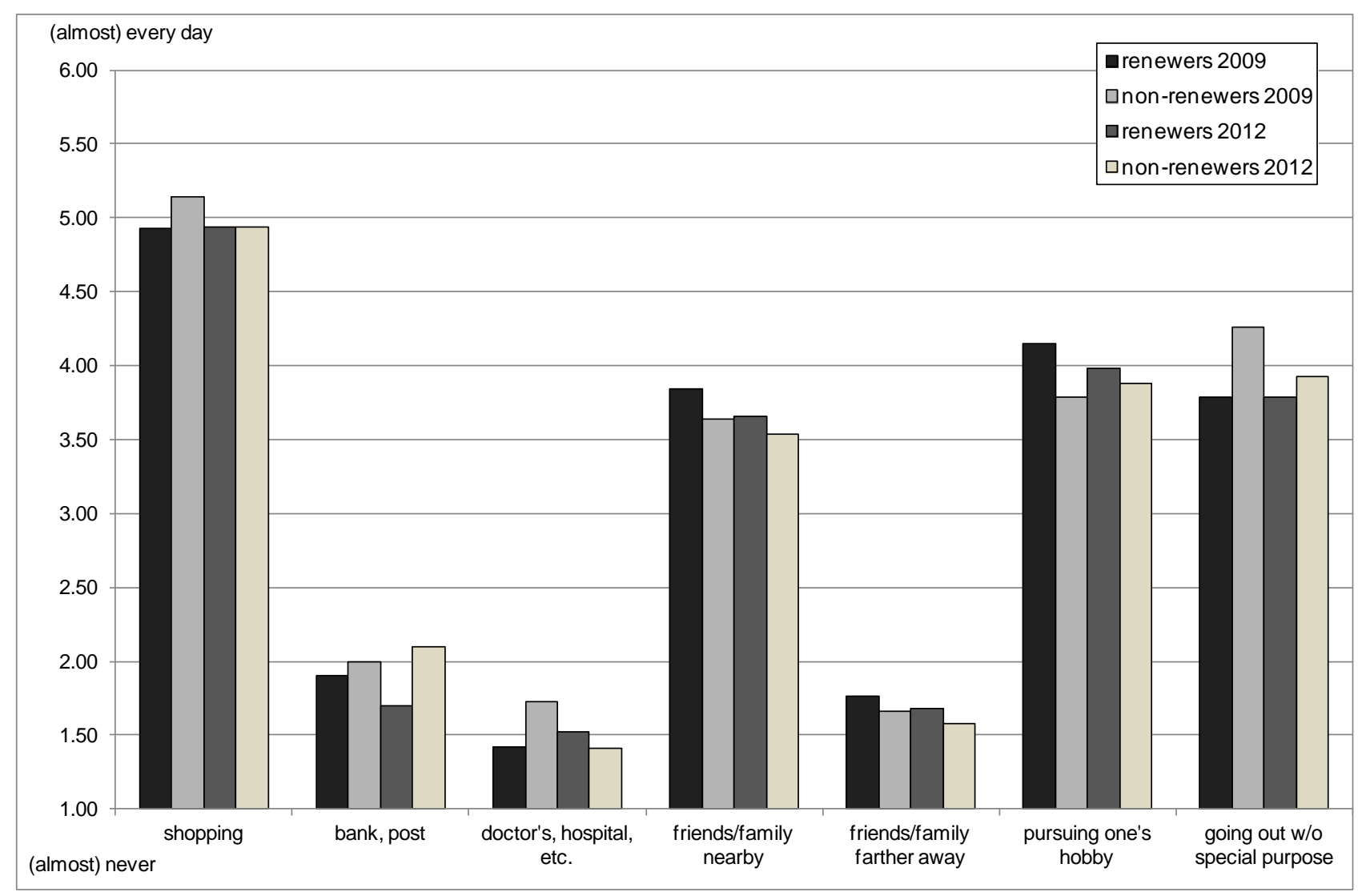

Figure 1: Activity frequency for renewers and non-renewers 2009 and 2012 


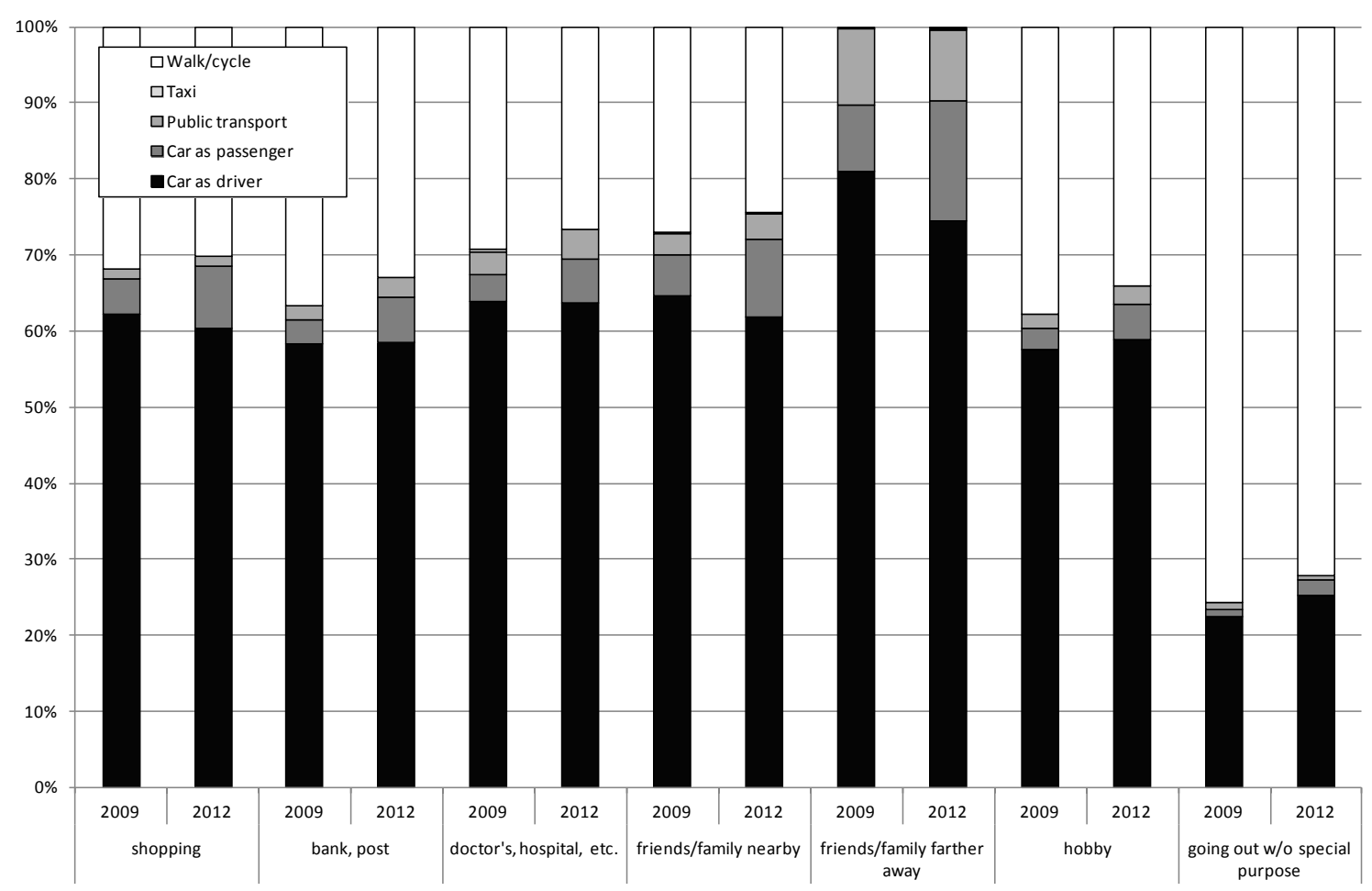

Figure 2: Main transport modes for renewers in 2009 and 2012. 


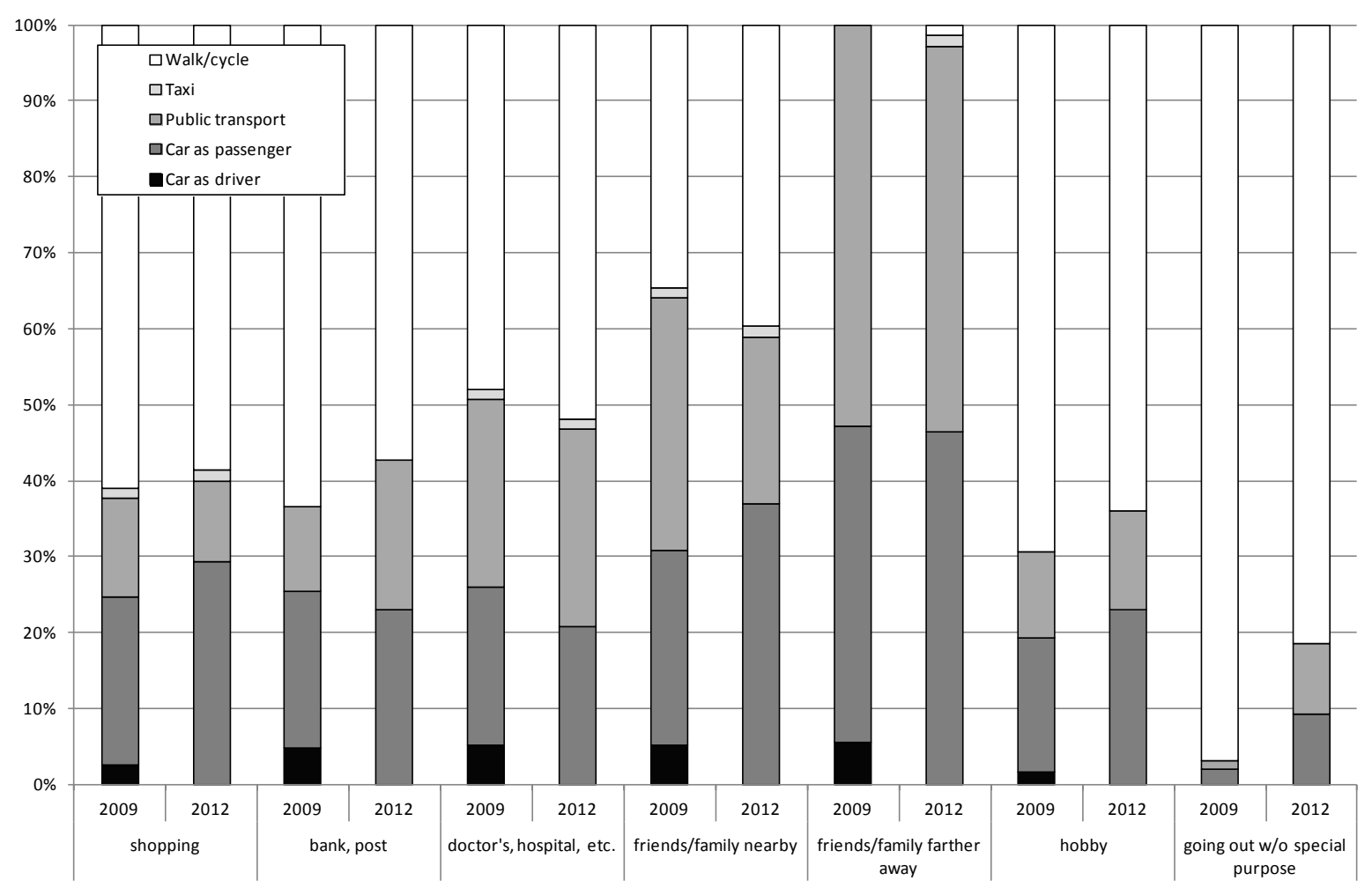

Figure 3: Main transport modes for non-renewers 2009 and 2012 


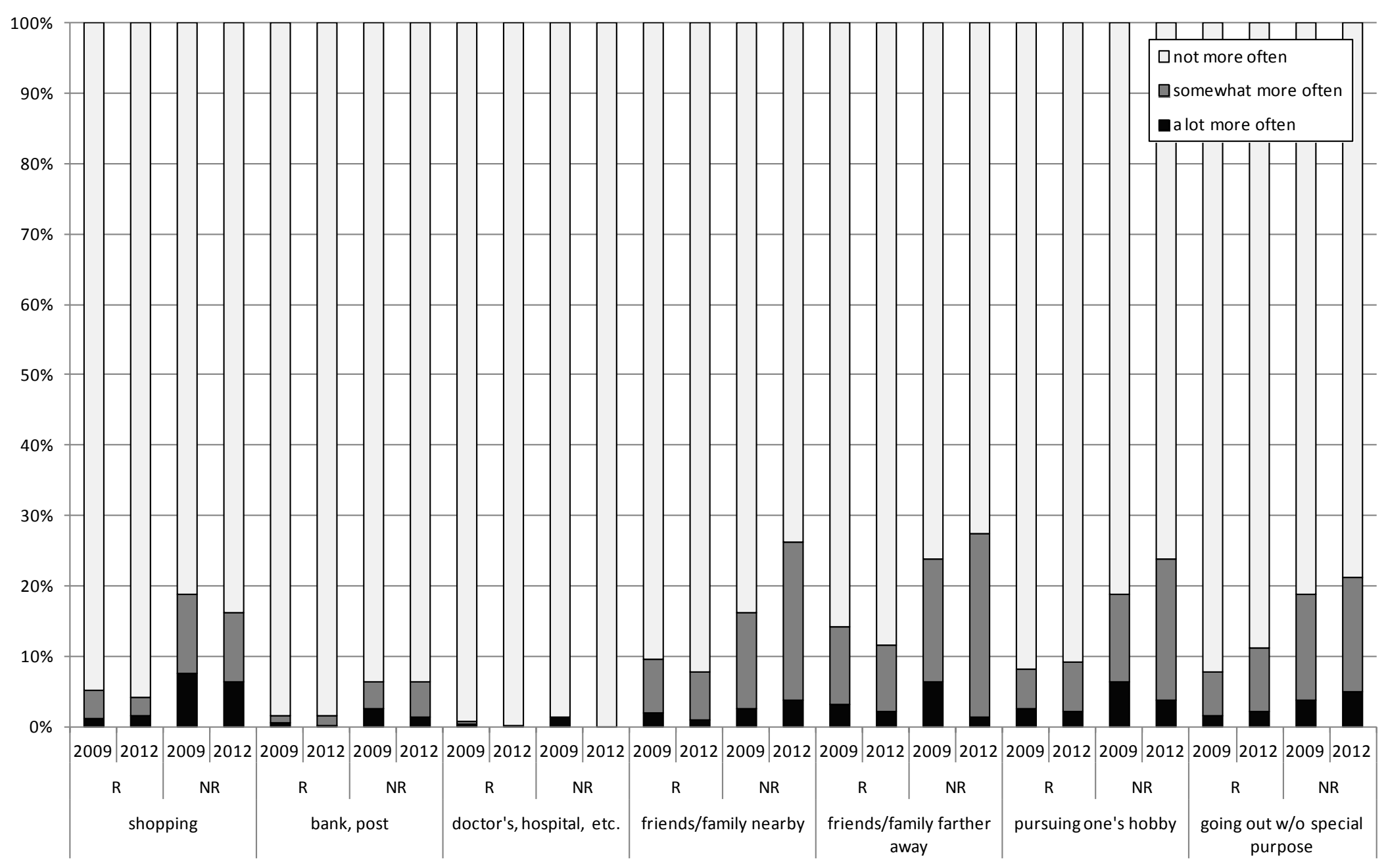

Figure 4: Unmet travel needs for renewers (R) and non-renewers (NR) in 2009 and 2012 